\title{
TENDÊNCIA E VARIABILIDADE ANUAIS DA TEMPERATURA E DA PLUVIOSIDADE EM PIRASSUNUNGA-SP
}

\author{
FERRARI, Antonio Luiz - aferrari@sc.usp.br \\ Centro de Recursos Hídricos e Ecologia Aplicada/USP - Univ. de São Paulo \\ VECCHIA, Francisco Arthur da Silva - fvecchia@sc.usp.br \\ Centro de Recursos Hídricos e Ecologia Aplicada/USP - Univ. de São Paulo
}

COLABONE, Rosângela de Oliveira - rocolabone@uol.com.br

Academia da Força Aérea/SP

\begin{abstract}
RESUMO. O objetivo deste trabalho é aplicar a análise estatística para identificação das tendências anuais da temperatura e da precipitação na região de Pirassununga - SP, bem como a variabilidade desses elementos climáticos. Utilizou-se a série histórica de 1976 a 2008, referentes à precipitação e temperatura, registradas pela estação

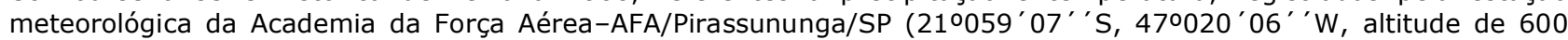
$\mathrm{m})$. Foram considerados, para o estudo da precipitação, os totais anuais e, para as máximas e mínimas absolutas anuais e a média das máximas e das mínimas. Para a análise da tendência utilizou-se a regressão linear que permitiu a obtenção dos coeficientes de determinação R2, erro padrão das estimativas e os limites de confiança. Para a avaliação da tendência climática, tanto da temperatura, quanto da precipitação, foram utilizados, também, os testes estatísticos não-paramétricos de Mann-Kendall e a Curvatura de Sem, que mostram, respectivamente, a significância da tendência e sua magnitude. A análise da série histórica considerada, no que se refere às temperaturas máximas, mínimas e médias máximas e mínimas, permitiu constatar regimes térmicos mais amenos em determinados anos do período estudado, destacando-se os anos considerados "normais" em relação aos acentuadamente mais quentes para a região. A pesquisa indicou que, nos últimos seis anos da série, houve estabilidade em relação às temperaturas mínimas. A maior amplitude térmica observada (39 ${ }^{\circ} \mathrm{C}$ ) ocorreu em 1994, que poderia ser definido como um ano excepcional. Apesar dessas alterações, não se pode afirmar que as tendências verificadas estão relacionadas às mudanças climáticas globais. A análise dos parâmetros estatísticos obtidos para a precipitação, mostrou se há ou não tendência de diminuição ou aumento de valores pluviométricos, com destaque para alguns anos mais significativos.

Palavras-chave: temperatura; precipitação, regimes térmicos; tendência; variabilidade; análise estatística.

TREND AND VARIABILITY OF ANNUAL TEMPERATURE AND RAIN IN PIRASSUNUNGA-SP

ABSTRACT. The objective of this work is to apply statistical analysis to identify trends in annual temperature in the region of Pirassununga - SP, as well as the variability of this climatic element. Times series (1976-2008) of temperature and precipitation from the meteorological station of the Air Force Academy - AFA/Pirassununga-SP (210059'07"S 470020'06"W and $600 \mathrm{~m}$ altitude) were used.

In the study of precipitation annual totals were considered. The maximum and minimum absolute temperatures were considered as well as the maximum and minimum annual average. For trend analysis, linear regression was used to obtain the coefficients of determination R2, standard error of estimates and confidence limits. The analysis of time series considered in relation to maximum and minimum temperatures and average maximum and minimum average evidenced warmer thermal regimes in certain years of the studied period, highlighting the years considered "normal" from those markedly warmer for the region. The search indicated that over the past six years of the series, the minimum temperature was stable. The highest observed temperature range (390C) occurred in 1994, which could be defined as an exceptional year. Despite these changes, we can not say that the trends are related to global climate change. The analysis of the obtained parameters, for precipitation show there is tendency of decrease or increase of pluviometric valuables or not, with eminence for some significative years.

Key-words: temperature; precipitation, thermal regimes; tendency, variability, statistical analysis.
\end{abstract}

\section{INTRODUÇÃO}

Uma das grandes preocupações do meio científico-acadêmico nos últimos anos diz respeito às mudanças climáticas e suas consequências em relação a todas as implicações de âmbito social, ambiental e econômico. Tais preocupações em relação às alterações climáticas devem-se ao fato que, desde meados do século passado, o clima do planeta vem apresentando comportamento com grande variação.

Segundo Christofoletti (1993), o clima pode ser considerado como o elemento condicionador da dinâmica do meio ambiente com influência direta nos processos de ordem física e biológica, assim como nos sistemas socioeconômicos de um modo geral, constituindo-se, portanto, um recurso essencial para a vida e para as atividades humanas.

Embora, no passado, o clima não fosse sempre idêntico e suas oscilações possibilitassem tanto o surpreendente desenvolvimento da vida no planeta, quanto à destruição dela decorrente de desastres e catástrofes, ainda causa perplexidade à repercussão que os elementos do clima exercem sobre nossas vidas. (SANT'ANNA NETO E ZAVATTINI, 2000). 
A preocupação, de certa forma exagerada e generalizada, em relação aos desastres que possivelmente podem estar vinculados às mudanças e impactos climáticos, advém do fato de existirem mais de 6 bilhões de pessoas ocupando a superfície do planeta, a grande maioria em condições ambientais precárias e altamente vulneráveis às catástrofes que possam ocorrer. De acordo com Vianello e Alves (1991), Conti (1993; 2000), Lombardo (1994) e Tavares (2001), a maioria dos fatores responsáveis pelos mecanismos causadores de mudanças do clima são, os de ordem natural, relacionados a parâmetros orbitais da Terra, à frequência de rotação, à intensidade de radiação solar, à quantidade de poeira atmosférica, destacando-se, também, o decréscimo da salinidade do Atlântico Norte, as anomalias na temperatura oceânica e a complexidade do sistema interativo Terra-Oceano-Atmosfera. Os estudos de dados climáticos realizados nos Estados Unidos por Karl et al. (1996), mostraram que, embora a temperatura tenha apresentado um incremento razoável nas últimas décadas, as variações não são tão grandes nem temporalmente consistentes, podendo-se levantar a hipótese que as mudanças tenham ocorrido por alterações aleatórias naturais.

O aquecimento global tem implicação direta na alteração da frequência e distribuição de chuvas, podendo aumentar as ocorrências de secas e de cheias.

Sendo assim, a importância do conhecimento da variabilidade dos elementos climáticos em nível regional e local é destacada por Bessat (2003), Nunes (2003), Paciornik (2003) como uma maneira de contribuir para a compreensão dela em nível global. A variabilidade e tendência da temperatura e precipitação em várias regiões do Estado de São Paulo foram estudadas por Zavattini (1983), Christofoletti (1991), Sant'Anna Neto (1995), Galina (2002), Roncato (2002), Tavares (2001) e Bieras (2006), observando-se que, em determinadas localidades, a temperatura teve um pequeno acréscimo em certos períodos e decréscimos, em outros, bem como tendência de diminuição ou aumento da precipitação.

Nesse sentido, este trabalho visa a contribuir, também, com os estudos sobre o comportamento do clima em escala local, utilizando para isso a análise estatística para identificação de tendências anuais da temperatura e precipitação, bem como sua variabilidade ao longo da série histórica considerada.

\section{MATERIAIS E MÉTODOS}

Para a análise das condições climáticas com a finalidade de se conhecer a variabilidade e a tendência da temperatura e da precipitação no município de Pirassununga - SP, foram utilizados os dados de uma série temporal de 33 anos (1976 a 2008), fornecidos pela estação meteorológica localizada no aeródromo da AFA - Academia da Força Aérea de PirassunungaSP (latitude 210059'07' 'S, longitude 47/]020'06' 'W e altitude de $600 \mathrm{~m}$ ), e pelo Instituto de Controle do Espaço Aéreo - ICEA de São José dos Campos/SP, órgão responsável pelo banco de dados meteorológicos da Aeronáutica.

De posse dos dados, foi usado o programa Excel para a produção de planilhas e, assim, geração das tabelas e gráficos representativos das condições anuais, com aplicação, em seguida, dos cálculos para a verificação da tendência e variabilidade da precipitação e da temperatura.

Para a avaliação da precipitação foram considerados os totais anuais e em relação à temperatura, foram consideradas as máximas e mínimas absolutas anuais e a média das máximas e das mínimas.

Para a análise da tendência, que visa a identificar se ocorre manutenção, aumento ou diminuição dos valores dos atributos climáticos dentro de uma série temporal, aplicou-se a técnica da regressão linear baseada no método dos mínimos quadrados, que consiste no ajuste de uma reta a um conjunto de pontos. Esses procedimentos foram utilizados por Christofoletti (1992), Sentelhas et al. (1994), Back (2001), Roncato (2002), Galina (2002), Bieras (2006), entre outros. O método dos mínimos quadrados busca minimizar a soma dos quadrados das 
diferenças entre os valores observados e os valores correspondentes na reta de tendência determinada pela equação

$$
\mathrm{Y}=\mathrm{Ymed}+\mathrm{mX}
$$

onde: $\mathrm{X}$ e $\mathrm{Y}$ são as variáveis e $\mathrm{m}=\Sigma(\mathrm{XY}) / \Sigma \mathrm{X} 2$.

As mesmas tabelas e gráficos permitiram, também, o cálculo dos coeficientes de determinação (R2), que mostram, por meio da estatística descritiva, as tendências resultantes, o erro padrão das estimativas e os limites de confiança. É preciso acentuar que o valor de $\mathrm{R}$ mede o grau de relação correspondente ao tipo de equação utilizada e, se o valor de $\mathrm{R}$ for próximo de zero, significa que quase não há correlação linear entre as variáveis. As fórmulas e a metodologia utilizadas no texto podem ser encontradas em Morettin e Bussab (2004). No caso de R2, seus valores variam entre -1 e 1 , sendo que, quanto mais próximo de 1 , mais significativo o valor da correlação e tendência. Galvani (2005) mostra como trabalhar os princípios básicos da Estatística Descritiva para uma melhor análise dos dados obtidos, mencionando, inclusive, a importância da equação da reta $Y=Y m e d+m X$ e do coeficiente de determinação R2. Gerardi e Silva (1981) afirmam que é desejável calcular o erro padrão das estimativas para indicar até que ponto os valores observados diferem dos valores estimados através da reta de regressão e, então, determinar os limites de confiança a serem colocados no gráfico.

Uma tendência climática é entendida como uma alteração do clima, aumento ou diminuição lenta dos valores médios da série de dados analisadas no período de registro.

$\mathrm{Na}$ análise das tendências de precipitações foram considerados dados de uma série com totais anuais, e esses dados foram submetidos a testes estatísticos não-paramétricos, conhecidos como testes de Mann-Kendall e Curvatura de Sen. O teste estatístico não-paramétrico de Mann-Kendal considera que, na hipótese de estabilidade de uma série temporal, a sucessão de valores ocorre de forma independente, e a distribuição de probabilidade deve permanecer sempre a mesma (série aleatória simples). De acordo com Önöz e Bayazit (2003), os benefícios desse teste são que: os dados não precisam pertencer a uma distribuição particular e que o resultado dele é menos afetado outliers, pois o cálculo baseia-se no sinal das diferenças e não diretamente nos valores da variável.

\section{ESTIMATIVA DAS TENDÊNCIAS}

A estimativa da magnitude das tendências pode ser realizada pelo cálculo do coeficiente angular da equação da reta obtida com a utilização do método de regressão linear, mas este coeficiente pode desviar-se muito do valor verdadeiro da inclinação da reta, se na série de dados existirem valores extremos (GILBERT, 1983).

Para obter a inclinação das tendências da série, utiliza-se o Método de Sen (1968) estendido por Hirsch et al. (1984). No Método de Sen a estimativa da inclinação que indica uma possível tendência é obtida pelo cálculo dos pares de valores da série $x_{1}, x_{2}, x_{3}, \ldots, x_{n}$ com a aplicação da fórmula abaixo

$$
S_{e}=\frac{x_{j}-x_{i}}{j-i}
$$

onde, $S_{e}$ é o valor estimado da inclinação de Sen, ou seja, o acréscimo ou decréscimo em função do tempo é dado pela seguinte expressão $f(t)=S_{e} t+B$, onde B uma constante. O teste de Sen possibilita identificar se houve, ou não, mudança de tendência e a magnitude na série, sendo uma técnica muito utilizada para a verificação da magnitude, (DEO et al., 2007 , YUE e HASHINO, 2003). 


\section{DETERMINAÇÃO DA SIGNIFICÂNCIA ESTATÍSTICA DAS TENDÊNCIAS}

Para determinar a significância estatística das variáveis estudadas, foram aplicados testes estatísticos de análises não-paramétricas de Mann-Kendall, proposto inicialmente por Sneyers (1975). O teste de Mann-Kendall considera que os dados precisam ser variáveis aleatórias independentes e identicamente distribuídas. As características desse teste são importantes quando aplicados às séries climatológicas, como precipitação, porque não dependem do tipo de série temporal. Goossens \& Berger (1986) afirmam que o teste de Mann-Kendall é apropriado para analisar mudanças climáticas em séries temporais porque permite a detecção e localização aproximada do ponto inicial de determinada tendência.

\section{FÓRMULAS DA ESTATÍSTICA DE MANN-KENDALL}

Para um conjunto de dados $x_{1}, x_{2}, x_{3}, \ldots, x_{n}$, com $n>4$, o teste estatístico de Mann-Kendall $S$, usa as seguintes fórmulas para a estatística de Mann-Kendall, como sendo:

onde a função sign é:

$$
S=\sum_{k=1}^{n-1} \sum_{j=k+1}^{n} \operatorname{sign}\left(x_{j}-x_{k}\right)
$$

A variância de $S$, denotada por $[\operatorname{Var}(S)]$, é definida por

$$
\begin{aligned}
\operatorname{sign}\left(x_{j}-x_{k}\right) & =\left\{\begin{array}{ccc}
1 & \text { se } & x_{j}-x_{k}>0 \\
0 & \text { se } & x_{j}-x_{k}=0 \\
-1 & \text { se } & x_{j}-x_{k}<0
\end{array}\right. \\
\operatorname{Var}(S) & =\frac{n(n-1)(2 n+5)}{18}
\end{aligned}
$$

e, com repetições de dados, a variância fica sendo:

$$
\operatorname{VAR}(S)=\frac{1}{18}\left[n(n-1)(2 n+5)-\sum_{p=1}^{g} t_{p}\left(t_{p}-1\right)\left(2 t_{p}+5\right)\right]
$$

onde, $g$ é número de grupos com dados repetidos e $t_{p}$ é o número de dados no $\mathrm{p}$-ésimo grupo. Logo $S$ e $\operatorname{Var}(S)$ são utilizados para o cálculo da estatística $Z$, com distribuição normal padrão:

$$
Z=\left\{\begin{array}{ccc}
\frac{S-1}{[\operatorname{VAR}(S)]^{\frac{1}{2}}} & \text { se } \quad \mathrm{S}>0 \\
0 & \text { se } \quad \mathrm{S}=0 \\
\frac{\mathrm{S}+1}{(\operatorname{VAR}(\mathrm{S}))^{\frac{1}{2}}} & \text { se } & \mathrm{S}<0
\end{array}\right.
$$


Para a análise da tendência utiliza-se valor de $Z$. Um valor positivo de $Z>0$ significa uma tendência crescente e um valor negativo $Z<0$, uma tendência decrescente.

O nível de significância $\alpha$ adotado é de $\alpha=0,05=5 \%$ para o Teste de Mann-Kendall. Se a probabilidade $p$ do Teste de Mann-Kendall for menor que o nível $\alpha, p<\alpha$, uma tendência estatisticamente significante existe, enquanto, um valor de $p>\alpha$, confirma uma tendência insignificante. Para amostras onde não há tendências, o valor de $Z$ é próximo de zero. Maiores detalhes sobre a metodologia são encontrados em Mann (1945), Kendall (1975), Hirsch e Slack (1984) e Gilbert (1983).

\section{RESULTADOS E DISCUSSÃO}

São apresentados a seguir e em seqüência os gráficos de regressão linear, análises das tendências e estimativas relativas ao período estudado. Com relação ao comportamento anual da temperatura durante a série temporal analisada (1976-2008), observa-se que as temperaturas máximas variam de $33^{\circ} \mathrm{C}$ em 1992 até $39^{\circ} \mathrm{C}$ em 1997 e 2008 e, as mínimas, de $2^{\circ} \mathrm{C}$ em 1994 até $7^{\circ} \mathrm{C}$ em 1992. A maior amplitude térmica observada $\left(39^{\circ} \mathrm{C}\right)$ ocorreu em 1994 , podendo-se considerá-lo um ano excepcional. A análise das temperaturas máximas do período de 1997 a 2007 mostra uma variabilidade bastante acentuada.

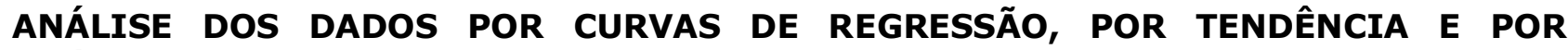 GRÁFICOS}

A observação dos últimos seis anos da série revela que houve pouca variabilidade em relação às temperaturas mínimas, mas, no período de 1997 a 2008, as temperaturas máximas voltaram a apresentar clara tendência de ascensão (Gráfico 1).

Pela análise das médias das temperaturas máximas e mínimas (Gráfico 2), é possível concluir que 1998 foi o ano mais quente, com a média das temperaturas máximas igual a $34,04^{\circ} \mathrm{C}$ e a média das mínimas, igual a $11,58^{\circ} \mathrm{C}$; e, 2004 foi o ano mais frio, com a média das temperaturas máximas igual a $31,16^{\circ} \mathrm{C}$ e a média das mínimas igual a $8,27^{\circ} \mathrm{C}$. Embora a menor temperatura da série seja de $-2^{\circ} \mathrm{C}$, ocorrida em 1994 , a amplitude térmica e as médias das máximas e mínimas não mostram que esse ano foi o mais frio do período. De 1976 até 1983 inexistiram grandes oscilações dos valores anuais em torno da média das temperaturas máximas, mas, após 1984, os dados apresentaram uma variabilidade um pouco mais acentuada, até atingir a menor das médias $\left(31,16^{\circ} \mathrm{C}\right)$, em 2004.

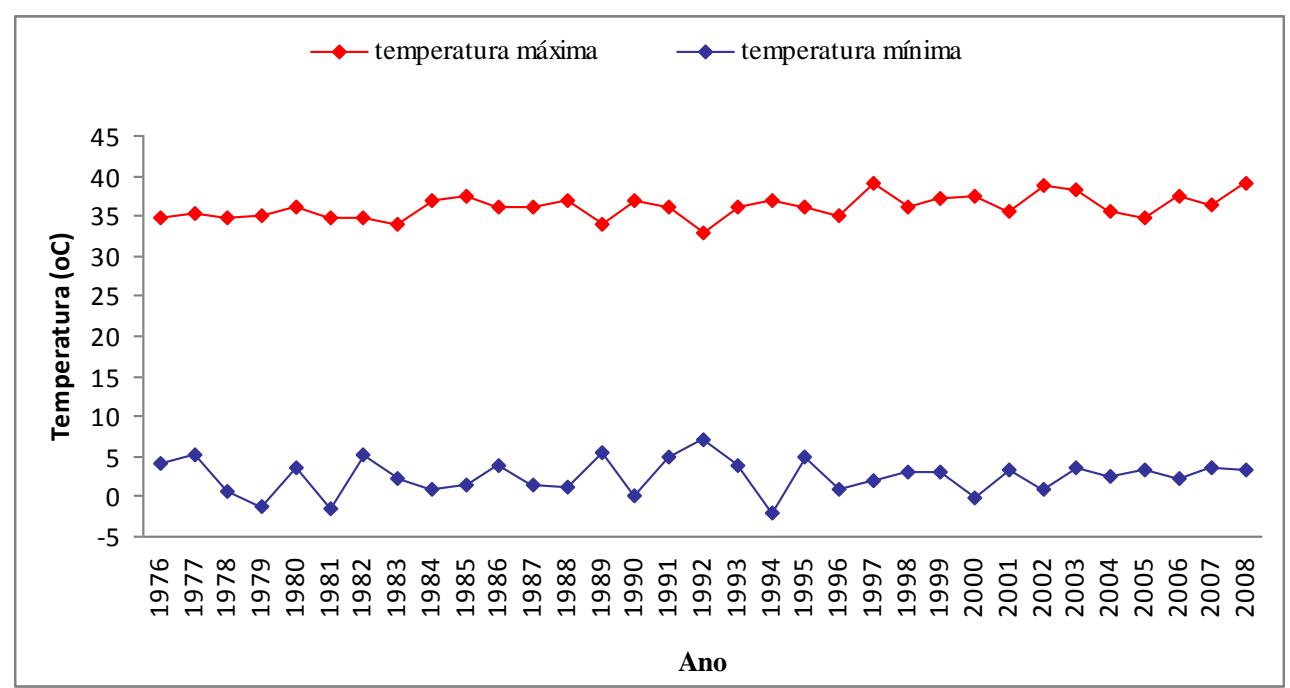

Gráfico 1. Temperaturas máximas e mínimas de Pirassununga/SP para o período 1976-2008. 


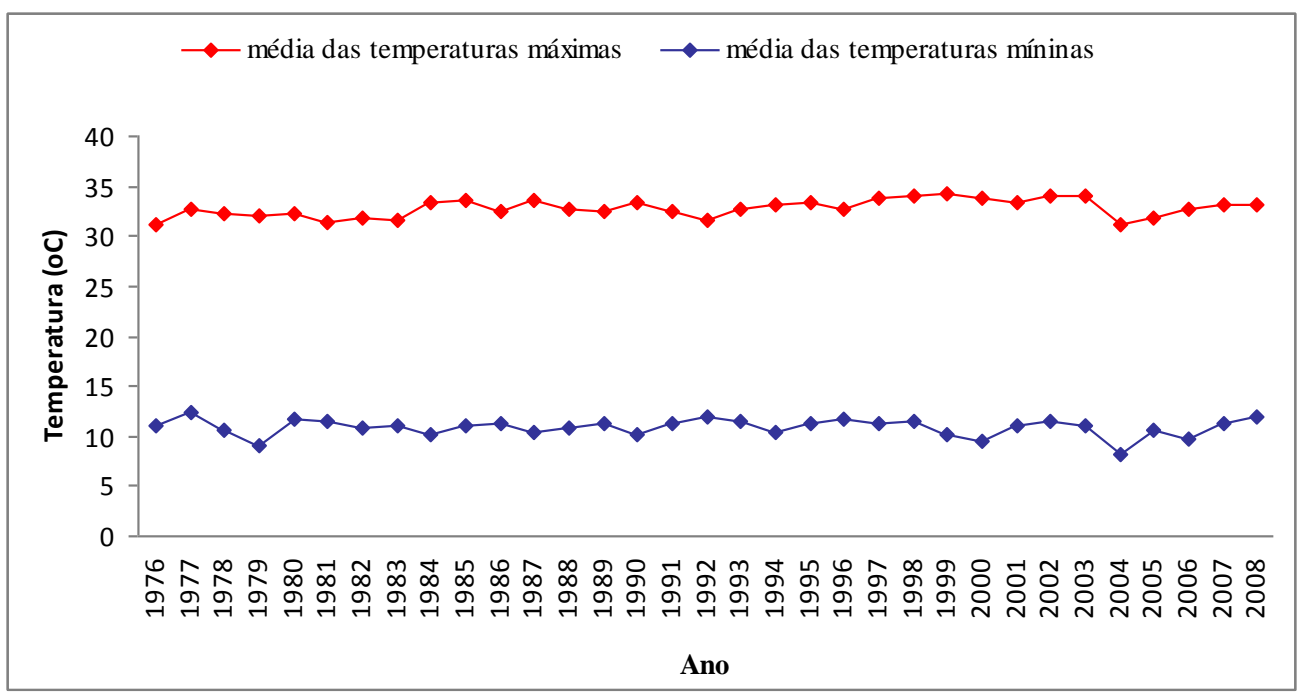

Gráfico 2. Médias das temperaturas máximas e mínimas de Pirassununga/SP para o período de 1976 a 2008.

A reta de regressão para a temperatura máxima, exibida no Gráfico 3, mostra que ela apresenta uma inclinação positiva com coeficiente angular bem acentuado. A reta ajustada aos dados do período apresentou um coeficiente de determinação igual a 0,23, mostrando uma pequena tendência a elevação da temperatura ao longo da série, mas pouca correlação entre a temperatura máxima e tempo cronológico. O número de valores confinados entre as hipérboles mostra um limite de confiança em torno de $50 \%$, revelando que metade das temperaturas máximas está entre $33^{\circ} \mathrm{C}$ e $39^{\circ} \mathrm{C}$.

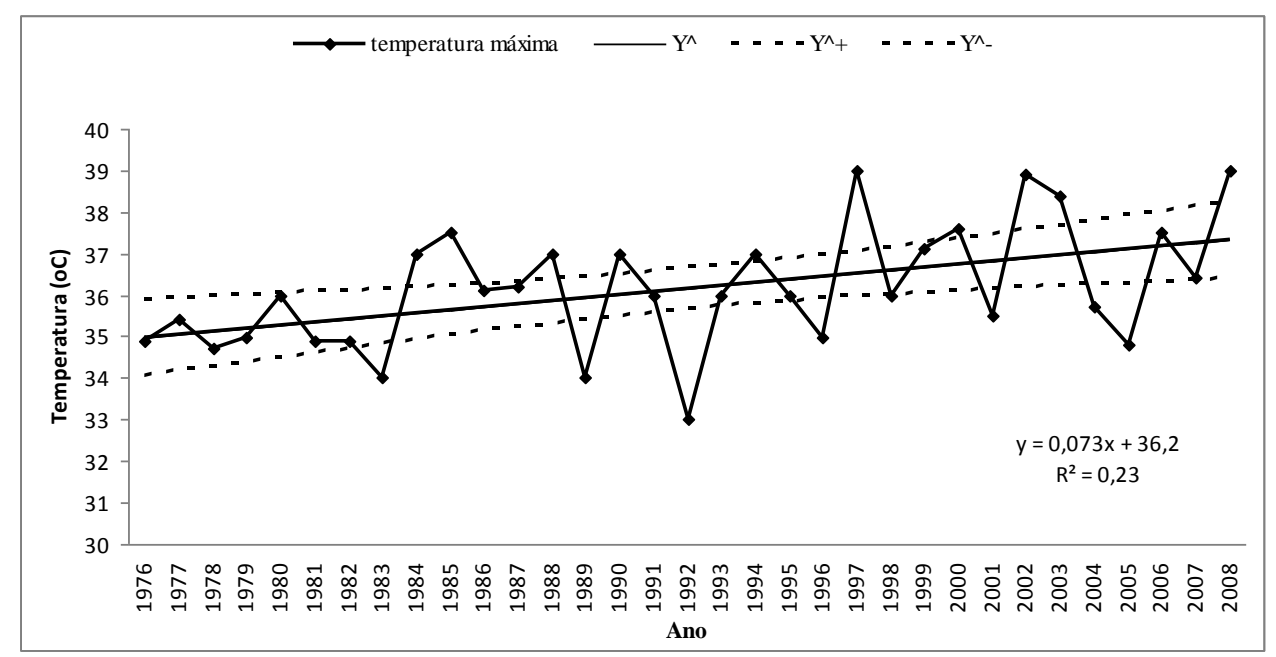

Gráfico 3. Reta de regressão e limites de confiança da temperatura máxima.

A análise da reta de regressão para a temperatura mínima (Gráfico 4) permite observar que o tempo cronológico não é um bom parâmetro de correlação com a temperatura mínima da série estudada, fato evidenciando pelo valor de $R^{2}=0,04$, ou seja, o grau de associação entre as duas variáveis é muito pequeno. Nesse caso, é possível que se trate de outro tipo de correlação não linear e que será estudado na continuidade deste trabalho. No entanto, os limites de confiança mostram que $48 \%$ dos valores da temperatura mínima estão entre $7^{\circ} \mathrm{C} \mathrm{e} \mathrm{-}$ $2^{\circ} \mathrm{C}$ e que os últimos dez anos da série apresentam uma tendência de estabilização. 


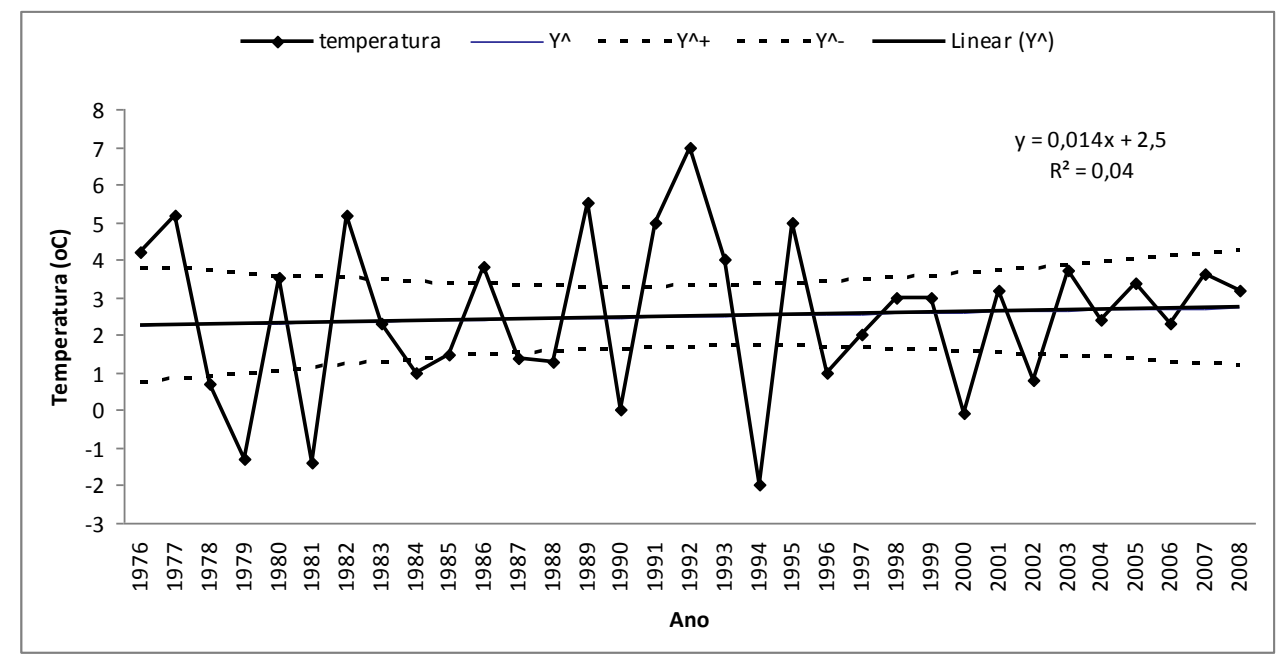

Gráfico 4. Reta de regressão e limites de confiança da temperatura mínima.

A reta de regressão para a média das temperaturas máximas (Gráfico 5) mostra uma clara tendência de aumento durante o período estudado. Embora o valor do coeficiente de determinação seja baixo, o comportamento da média das temperaturas máximas representa tendência estatística significativa (variação de $31,16^{\circ} \mathrm{C}$ até $34,29^{\circ} \mathrm{C}$ ).

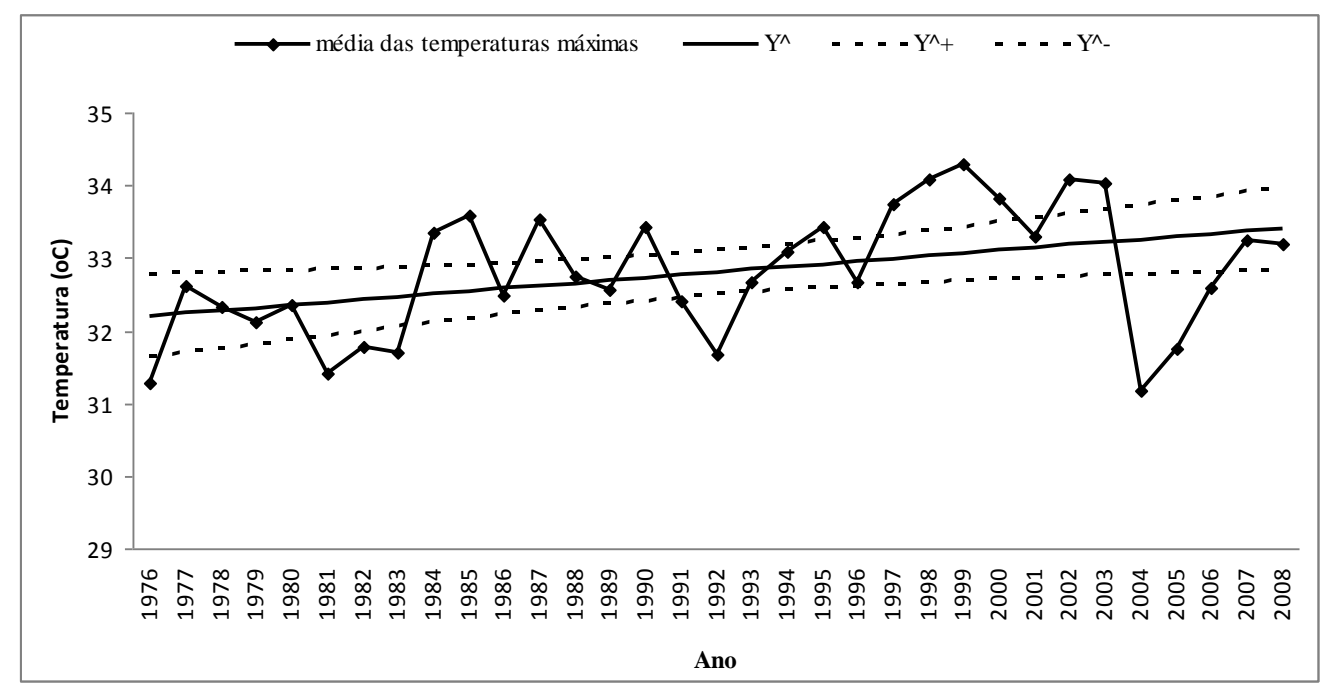

Gráfico 5. Reta de regressão e limites de confiança da média das temperaturas máximas.

Com relação à reta de regressão para a média das temperaturas mínimas (Gráfico 6), verificase uma grande dispersão dos pontos ao longo da reta, o que significa uma pequena correlação entre as variáveis $\left(R^{2}=0,02\right)$, pois os limites de confiança ficaram abaixo de $36 \%$, mostrando uma grande variabilidade e uma leve tendência à diminuição dos valores da média das temperaturas mínimas do período (coeficiente angular negativo). 


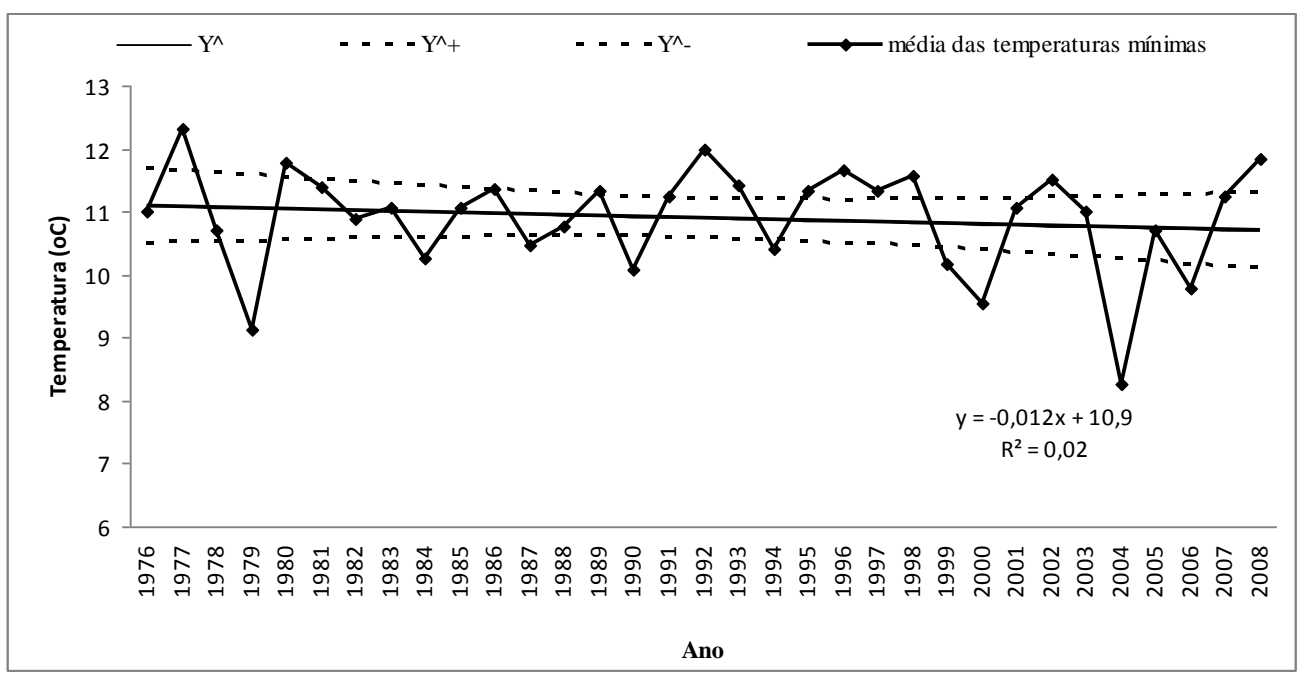

Gráfico 6. Reta de regressão e limites de confiança da média das temperaturas mínimas.

Para os dados das temperaturas anuais no período de 1976 a 2008, as curvas linear, exponencial, logarítmica e geométrica (obtidas dos aplicativos Statistica e BioEstat 3.0), apresentaram os coeficientes de determinação $\mathrm{R}^{2}$ iguais a $4.86 \%, 5.09 \%, 4.94 \%$ e 5,14\% respectivamente, observando-se que, nesse caso, a curva geométrica da forma $Y^{\prime}=0,0001 *$ $X^{\wedge} 3,3508$ é a que melhor se ajusta aos dados das temperaturas médias máximas anuais em relação às média mínimas anuais. A curva de regressão linear tem como equação $Y=31,6524$ $+0,1050 \mathrm{X}$, cujo gráfico (7) é apresentado a seguir.

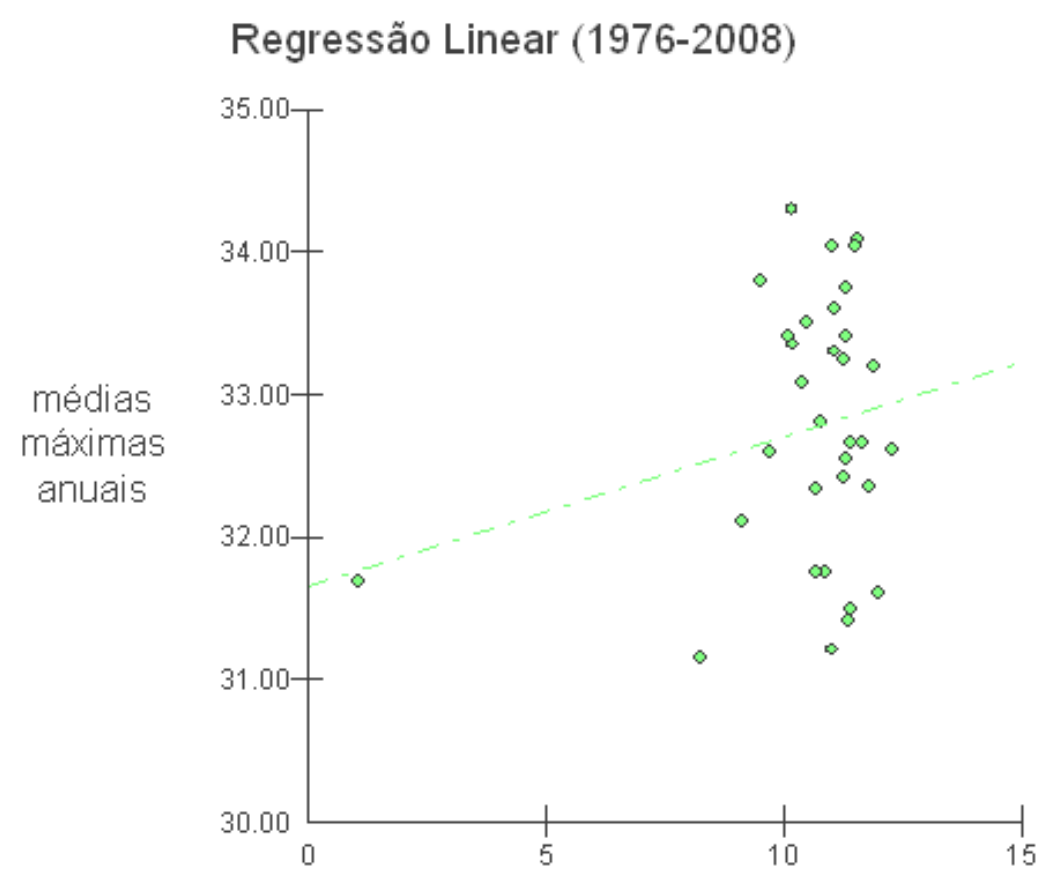

médias mínimas anuais

Gráfico 7. Reta de regressão linear das médias máximas em relação às médias mínimas.

No período de 1976 a 2008, a curva que melhor se ajusta aos dados é a polinomial de grau 4, cuja equação é da forma $Y=56,0129-29,5344 X+6,9823 X^{2}-0,6030 X^{3}+0,0177 X^{4}$, onde a variável independente é $X$ (mínimas anuais) e a variável dependente é $Y$ (máximas anuais) com coeficiente de determinação $R^{2}=0,1886$, (Gráfico 8).

Uma análise dos coeficientes de determinação para as curvas obtidas mostra que a mais ajustada é a da curva quártica (polinômio de grau 4). Isso pode ser útil nos estudos de 
previsão de dados por meio da curva que melhor se ajusta ao período estudado. Entretanto, o coeficiente de determinação $\mathrm{R}^{2}$ não está muito próximo do ideal, sendo necessário elaborar-se um estudo para uma série histórica que leve em consideração dados mais próximos para o período. Nesse caso é possível esperar um coeficiente de determinação mais próximo de 1 e outra equação melhor adaptada para esse fim, e não a equação das médias anuais.

Considerando-se o período de 1976-2008 para as temperaturas médias máximas, obtém-se a equação de regressão linear dada por $Y=-46,6416+0,0399 X$, onde $Y$ é a variável dependente das temperaturas máximas e $X$ a variável independente dos anos do período. De acordo com o gráfico 9, o coeficiente de determinação da equação é igual a $R^{2}=0,1790$. O coeficiente de correlação de Kendall é igual a $T=0,3036$, indicando que há pouca tendência de variação das temperaturas médias máximas no período de 1976-2008. Apesar de reduzida, a tendência é positiva.

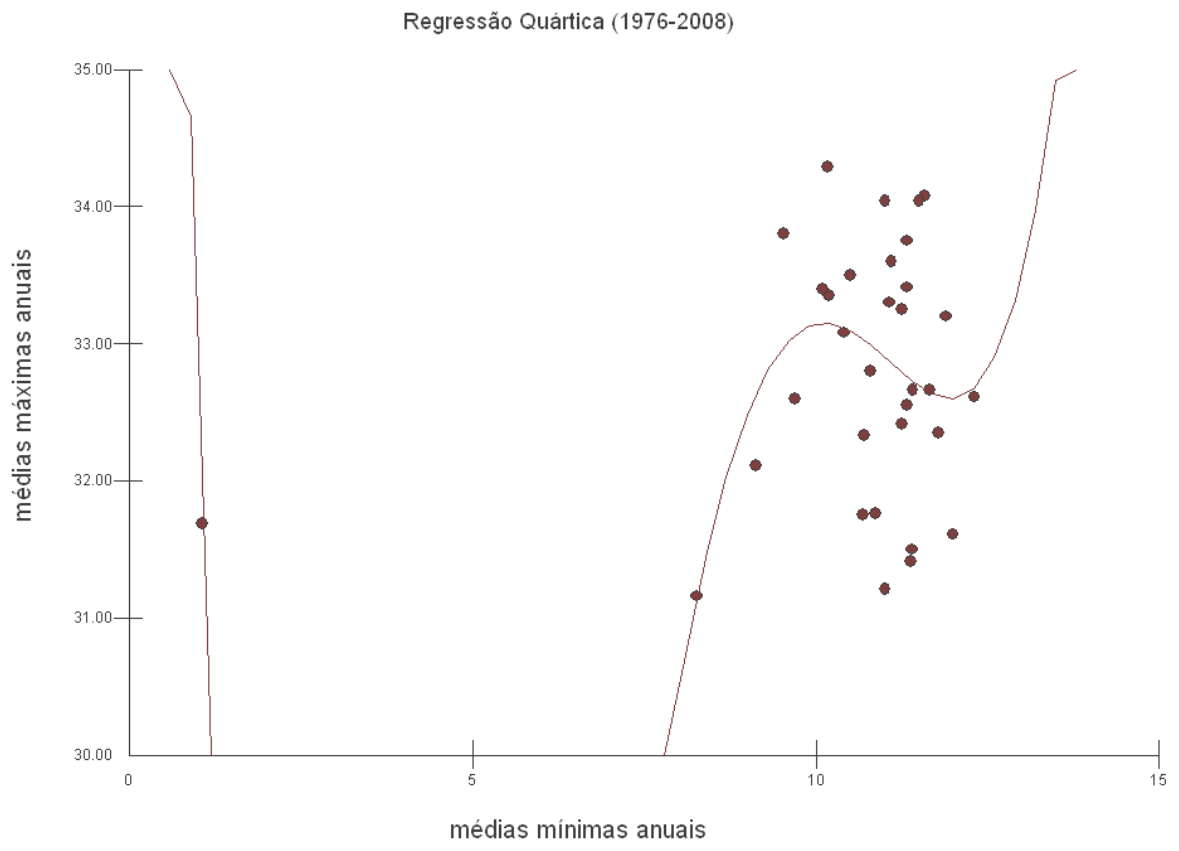

Gráfico 8. Curva polinomial de grau 4 das temperaturas médias máximas em relação às médias mínimas anuais. 


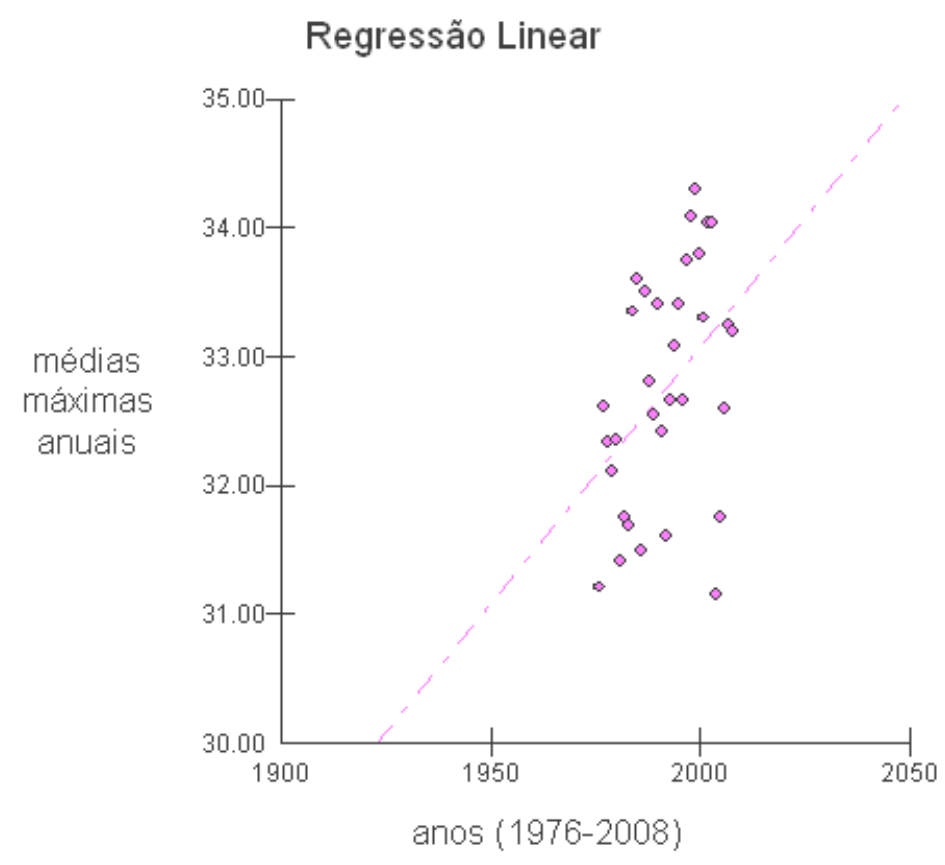

Gráfico 9. Reta de regressão linear das temperaturas médias máximas anuais em relação ao período considerado.

Para o período de 1976-2008 a curva de regressão quártica (polinômio de grau 4) apresenta uma equação dada por

$$
Y=1076508,71-1313,85 X+0,3478 X^{2}+0,0001 X^{3}+0,000003 X^{4}
$$

e coeficiente de determinação $R^{2}=0,2813$, conforme o gráfico 10 .

\section{Regressão Quártica}

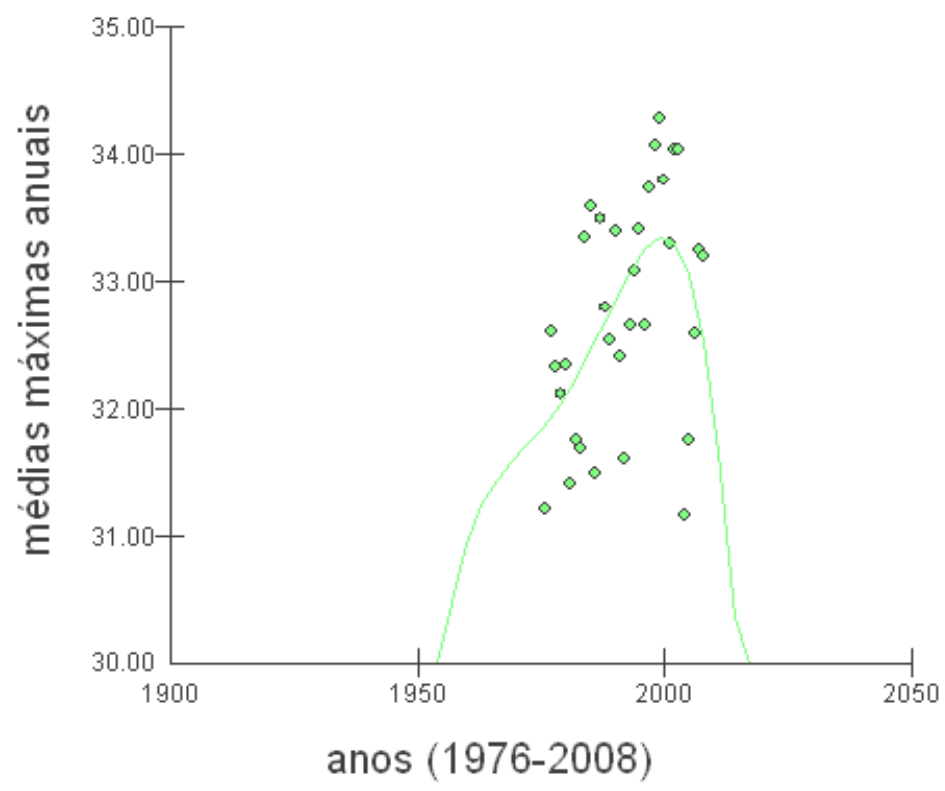

Gráfico 10. Curva de regressão quártica das temperaturas médias máximas anuais em função do período estudado.

Em relação ao estudo da precipitação para o período de 1976 a 2008, obteve-se a curva de regressão linear, tendo como variável dependente a precipitação para o período e, como variável independente o período de 1976-2008, mostrada pelo gráfico 11 . O coeficiente de 
determinação é $R^{2}=2,31 \%$ e a equação da curva de regressão linear é $Y=9847,7861-$ $4,2961 X$.

\section{Regressão Linear (Pirassununga 1976-2008)}

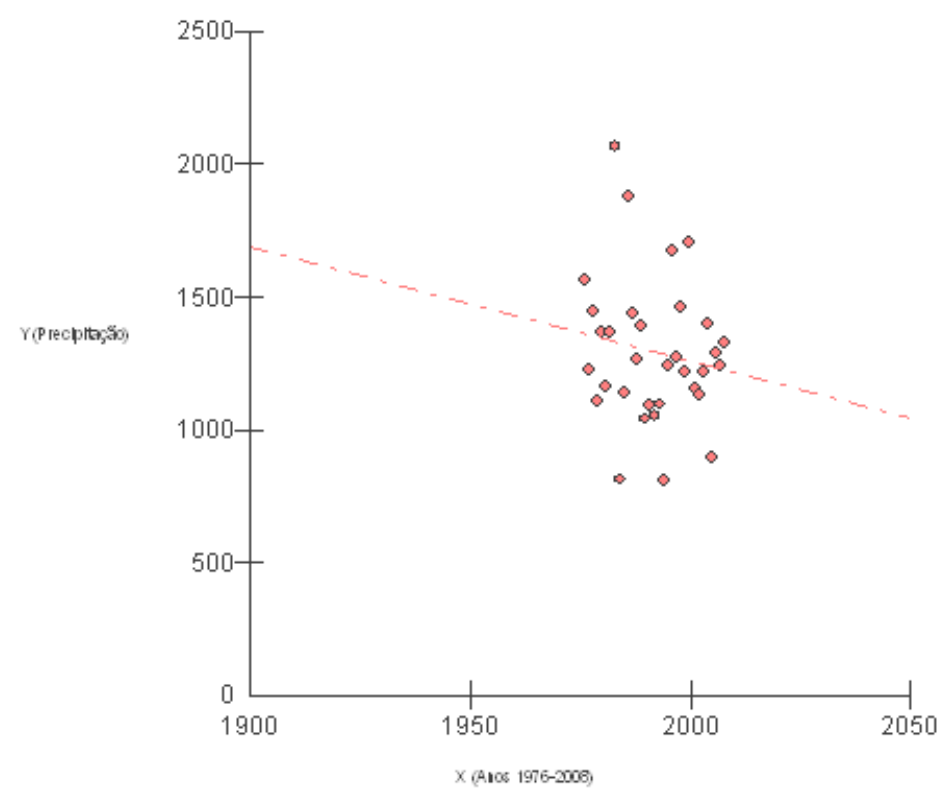

Gráfico 11. Curva de regressão linear da precipitação em função do período estudado.

A curva de regressão quártica (polinômio de grau 4) tendo como variável dependente, precipitação para o período de 1976-2008, e como variável independente o período de 19762008 , é mostrada no gráfico 12 . O coeficiente de determinação é $R^{2}=2,85 \%$ e a equação da curva de regressão linear é

$$
Y=24265720,7524-28389,2637 X+6,3138 X^{2}+0,0028 X^{3}+0,0001 X^{4} .
$$

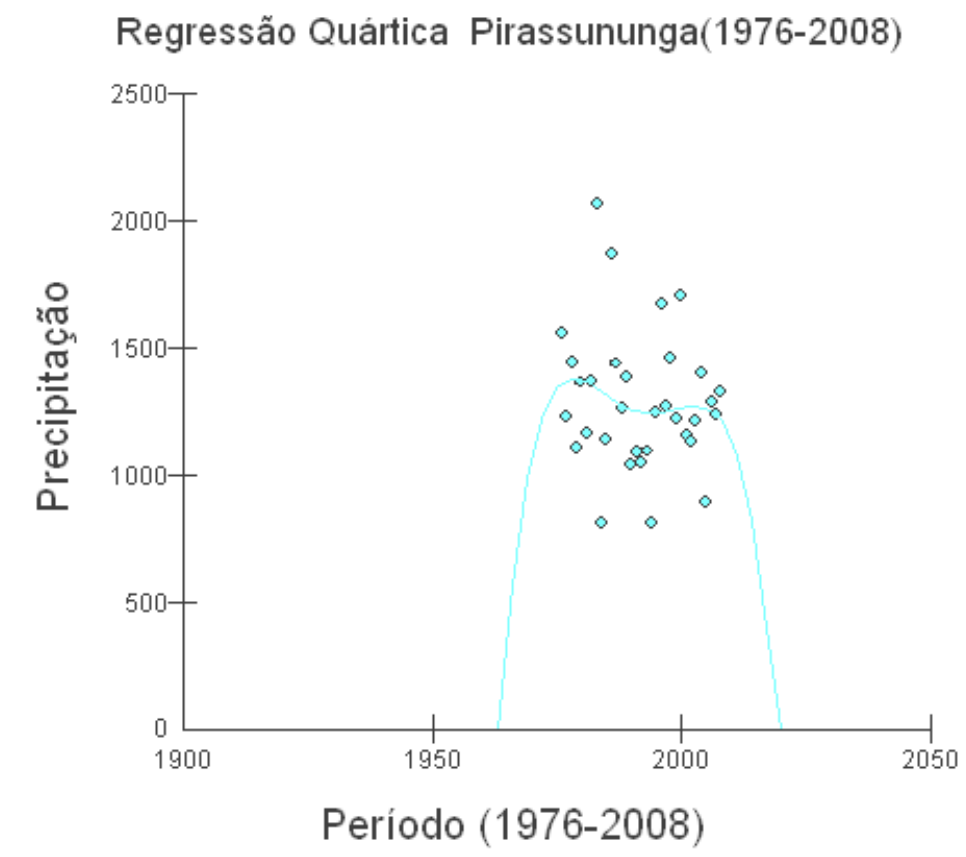

Gráfico 12. Curva de regressão quártica da precipitação em função do período estudado.

As principais Medidas Estatísticas para os dados de Pirassununga no período de 1976-2008 foram obtidas pelos aplicativos Statistica e BioEstat. 


\section{ANÁLISES DAS MEDIDAS ESTATÍSTICAS}

A seguir são apresentados nas tabelas 1 e 2 os resultados das principais medidas estatísticas obtidas com os aplicativos Satistica e Matlab.

Tabela 1

Medidas Estatísticas para os dados de Pirassununga no período de 1976-2008.

\begin{tabular}{lccccc}
\hline Estatística & $\begin{array}{c}\text { Vemperatura } \\
\text { Máxima } \\
\text { Média( }\left({ }^{\circ} \mathrm{C}\right)\end{array}$ & $\begin{array}{c}\text { Temperatura } \\
\text { Mínima } \\
\text { Média }\left({ }^{\circ} \mathrm{C}\right)\end{array}$ & $\begin{array}{c}\text { Temperatura } \\
\text { Máxima }\left({ }^{\circ} \mathrm{C}\right)\end{array}$ & $\begin{array}{c}\text { Temperatura } \\
\text { Mínima( }\left({ }^{\circ} \mathrm{C}\right)\end{array}$ & $\begin{array}{c}\text { Precipitação } \\
(\mathrm{mm})\end{array}$ \\
\hline Mínimo & 31,16 & 1,07 & 33,00 & $-2,0$ & 810,00 \\
Máximo & 34,29 & 12,31 & 39,00 & 7,00 & 2069,00 \\
Mediana & 32,66 & 11,07 & 36,00 & 3,00 & 1244,00 \\
Média Aritm. & 32,76 & 10,59 & 36,16 & 2,52 & 1289,90 \\
Desvio.Padrão & 0,91 & 1,91 & 1,48 & 2,14 & 273,60 \\
Assimetria & $-0,16$ & $-4,10$ & 0,20 & $-0,22$ & 0,80 \\
\hline
\end{tabular}

Com os dados da Tabela 1, calcularam-se as medidas descritivas tais como a média aritmética, máximo, mínimo, o desvio padrão, e o coeficiente de assimetria. As fórmulas para o cálculo dessas medidas podem ser encontradas em Moretin e Bussab (2004). Nesses cálculos utilizaram-se os programas estatísticos SAS e Statistica.

Pela Tabela 1, pode-se observar pela mediana que aproximadamente $50 \%$ dos anos estudados do período apresentaram temperaturas máximas e mínimas inferiores a $36^{\circ} \mathrm{C}$ e a $3^{\circ} \mathrm{C}$ respectivamente, sendo a dispersão (coluna do desvio padrão) desses dados maiores para as temperaturas máximas. Além disso, para a precipitação, a coluna da mediana mostra que $50 \%$ dos dados no período ocorreram com precipitações inferiores a $1244 \mathrm{~mm}$. Em relação à assimetria, as temperaturas máximas e precipitação são classificadas como assimétricas à direita, pois apresentam os coeficientes do momento de assimetria $a_{3}>0$ e as temperaturas máximas médias, mínimas médias e mínimas são consideradas assimétricas à esquerda, pois $a_{3}<0$.

\section{ANÁLISES DAS TENDÊNCIAS, DAS ESTIMATIVAS E DOS GRÁFICOS}

A seguir são apresentados os resultados das análises das tendências das variáveis meteorológicas de Pirassununga, no período de 1976-2008, a partir do teste estatístico de Mann-Kendall e Curvatura de Sen, considerando-se o nível de confiança de $95 \%$ ou $\alpha=5 \%$.

Tabela 2

\section{Análise Estatística das Variáveis Meteorológicas $(\alpha=5 \%)$}

\begin{tabular}{|c|c|c|c|c|c|}
\hline \multirow[b]{2}{*}{ Estatísticas } & \multicolumn{5}{|c|}{ Variáveis Meteorológicas } \\
\hline & $\begin{array}{c}\text { Temperatura } \\
\text { Máxima } \\
\text { Média }\left({ }^{\circ} \mathrm{C}\right)\end{array}$ & $\begin{array}{c}\text { Temperatura } \\
\text { Mínima } \\
\text { Média }\left({ }^{\circ} \mathrm{C}\right)\end{array}$ & $\begin{array}{l}\text { Temperatura } \\
\text { Máxima }\left({ }^{\circ} \mathrm{C}\right)\end{array}$ & $\begin{array}{l}\text { Temperatura } \\
\text { Mínima }\left({ }^{\circ} \mathrm{C}\right)\end{array}$ & $\begin{array}{c}\text { Precipitação } \\
(\mathrm{mm})\end{array}$ \\
\hline Escore Z & 2,1945 & $-0,3877$ & 2,9013 & 0,1187 & $-0,5733$ \\
\hline MannKendall & 0,2656 & $-0,0492$ & 0,3494 & 0,0160 & $-0,0720$ \\
\hline Curvat.Sen & 0,0393 & $-0,0065$ & 0,0800 & 0,0042 & $-3,1786$ \\
\hline Prob. (p) & 0,0282 & 0,6983 & 0,0037 & 0,9055 & 0,7221 \\
\hline
\end{tabular}


A partir da Tabela 2, é possível verificar que para os resultados:

- da coluna 1 (temperaturas máximas médias) e coluna 3 (temperaturas máximas), há uma tendência de 0,2656 e 0,3494 (Mann-Kendall), crescente ou positiva, pois Z>0, sendo significante, pois $p<\alpha$ e que essas temperaturas aumentam aproximadamente $0,0393^{\circ} \mathrm{C} \mathrm{e}$ $0,0800^{\circ} \mathrm{C}$ por ano, respectivamente (coluna curvatura de Sen), para a série temporal estudada;

- da coluna 2 (temperaturas mínimas médias), há uma tendência de -0,0492, fracamente decrescente ou negativa, pois $Z<0$, sendo insignificante, pois $p=0,6983>\alpha=0,05$, com uma diminuição de aproximadamente $-0,0065^{\circ} \mathrm{C}$ por ano;

- da coluna 4 (temperaturas mínimas), há uma tendência de 0,0160 crescente, pois $Z>0$, insignificante, pois $p>\alpha$, e que essas aumentam de aproximadamente $0,0042^{\circ} \mathrm{C}$ por ano;

- da coluna 5 (precipitação), há uma tendência de $-0,0720$ (decrescente) ou negativa, pois $\mathrm{Z}<0$, considerada insignificante, pois $p>\alpha$ com uma diminuição de aproximadamente $3,1786 \mathrm{~mm}$ por ano.

Para os dados das temperaturas máximas médias de Pirassununga no período de 1976-2008, é apresentado, a seguir o gráfico da regressão linear, construído pelo Matlab, considerando as estatísticas de Mann-Kendall igual a 0,2656, e curvatura de Sen igual a 0,0393 que resultou em tendência significante pela coluna 1 da Tabela 2 , e $p=0,0282<. \alpha=0,05$.

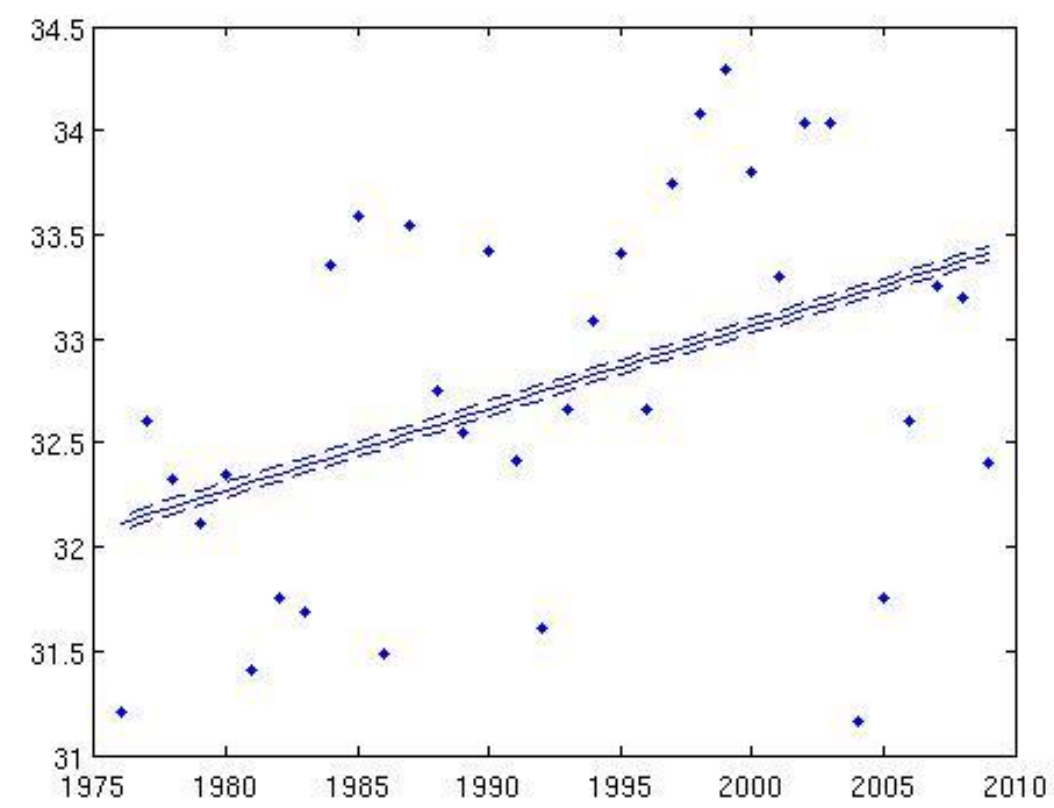

Gráfico 13. Temperaturas Máximas Médias de Pirassununga 1976-2008.

Para os dados das temperaturas máximas de Pirassununga no período de 1976-2008, é apresentado, a seguir o gráfico da regressão linear, construído pelo Matlab, considerando as estatísticas de Mann-Kendall igual a 0,3494, curvatura de Sen igual a 0,0800, que resultou em tendência significante pela coluna 3 da Tabela 2 , e $p=0,0037<. \alpha=0,05$. 


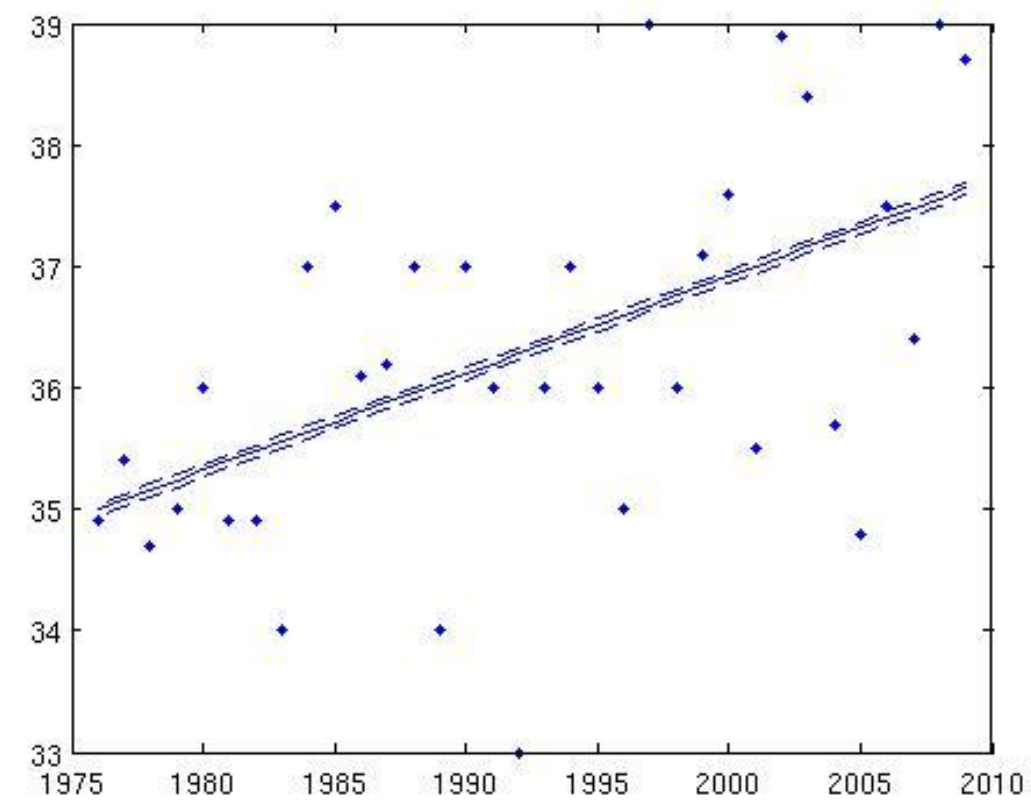

Gráfico 14. Temperaturas máximas de Pirassununga, 1976-2008.

A seguir, é mostrado o gráfico de barras para a precipitação de Pirassununga, 1976-2008.

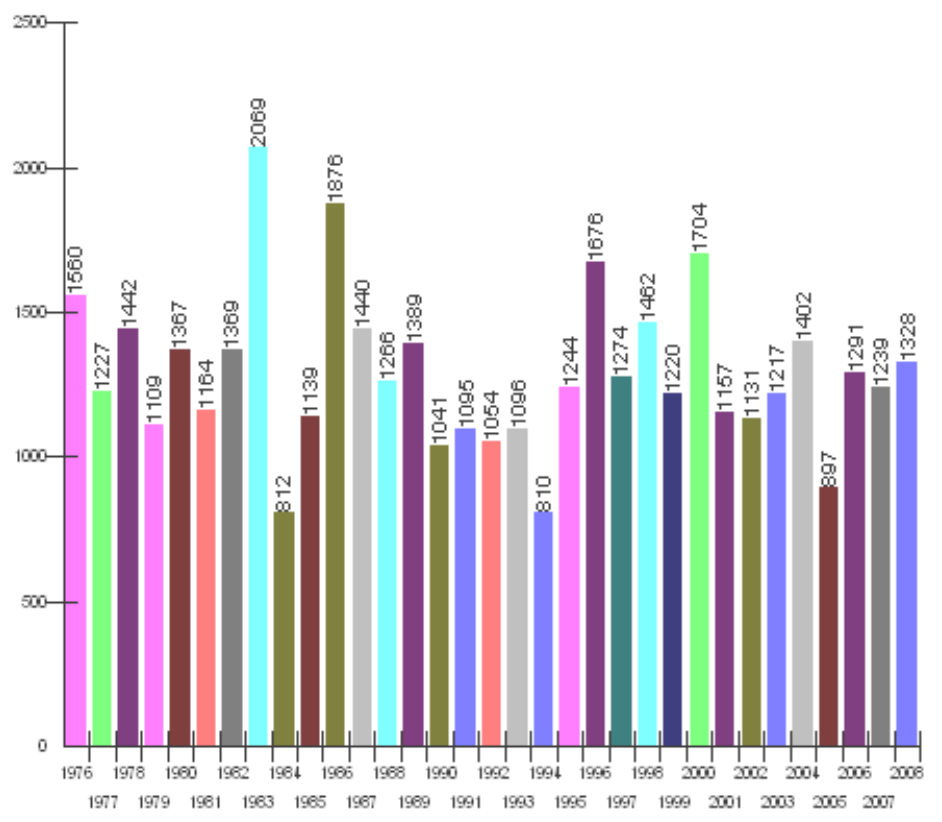

Gráfico 15. Gráfico de barras para a precipitação de Pirassununga, 1976-2008.

O gráfico 15, acima, ilustra a distribuição temporal da precipitação total anual no município de Pirassununga/SP, no período de 1976 a 2008. Constata-se que o menor valor de precipitação no município ocorre no ano de 1994, com um total precipitado anual de $810,7 \mathrm{~mm}$, ao passo que o maior valor anual precipitado foi de $2069,1 \mathrm{~mm}$, registrado em 1983, ressaltando-se a alta variabilidade temporal da precipitação naquela localidade. A precipitação total anual média nesse período é de 1282,2 mm, valor próximo da normal climatológica de (1971-2000), que é de $1367 \mathrm{~mm}$.

A observação da Tabela 2 e do Gráfico 15, permite concluir que não foi encontrada tendência significativa na variável precipitação analisada com teste Mann-Kendall. Folhes \& Fish (2006), 
analisando as séries de precipitação total anual no período de 1983 a 2005 em Taubaté/SP, também não encontraram tendência significativa para esta variável.

Os resultados obtidos nesta pesquisa são preliminares e para corroborar com o descrito, temse também, o trabalho desenvolvido por Berlato et al. (1995), que estudando dados de precipitação de 17 locais do Rio Grande do Sul, não identificaram tendências de longo prazo na precipitação pluvial anual, ressaltando que as reduções e incrementos que se observaram em curto período se referem, possivelmente, à flutuação natural da precipitação.

\section{CONSIDERAÇÕES FINAIS}

O estudo da variabilidade e tendência da temperatura, com utilização de uma série histórica, cuja variável dependente é o tempo, mostra que a grande maioria dos trabalhos publicados considera, com bastante frequência, os dados da temperatura média anual ou mensal, que apontam sempre para uma tendência central.

O presente trabalho estudou o comportamento das temperaturas máximas, mínimas, média das máximas e mínimas e das precipitações anuais, ao longo da série histórica, por considerar esses atributos climatológicos mais representativos e significativos, em relação à localidade escolhida.

Foram levantadas informações referentes ao comportamento da temperatura nos últimos 33 anos, dados que poderão ser úteis para auxiliar o planejamento de várias atividades desenvolvidas na região. O estudo indicou que não houve aumento significativo na média das temperaturas mínimas anuais, com ocorrência até, de uma tendência à estabilidade nas temperaturas mínimas anuais. Assim, embora com certa dificuldade para fazer afirmações exatas sobre o comportamento do clima, é possível considerar que não foram identificadas mudanças climáticas acentuadas durante esse curto prazo, na escala local no período de 1976 a 2008, e que as modificações ocorridas em relação à temperatura devem-se à variabilidade natural do clima. Isto foi constatado pelas análises das tabelas 1 e 2. O teste de Mann-Kendall foi aplicado no intuito de verificar se as variáveis meteorológicas estão indicando alguma tendência climática. A estatística de Mann-Kendall e a curvatura de Sen permitiram verificar se há alguma tendência de variação das temperaturas ou precipitação no período estudado.

Embora tenha ocorrido uma grande variabilidade temporal da precipitação na localidade estudada, as medidas estatísticas permitem concluir que não foi encontrada tendência significativa na variável precipitação analisada com teste Mann-Kendall. A pesquisa apresentou dados importantes, atingindo os objetivos propostos.

\section{REFERÊNCIAS}

.BACK, A. J. Aplicação de análise estatística para identificação de tendências climáticas. Pesquisa Agropecuária Brasileira, v. 36, n. 5, 2001.

.BERLATO, M. A.; FONTANA, D. C.; BONO, L. Tendência temporal da precipitação pluvial anual no Estado do Rio Grande do Sul. Revista Brasileira de Agrometeorologia, Santa Maria, v.3, p.111-113, 1995.

.BESSAT, F. A. A mudança climática entre ciência, desafios e decisões: olhar geográfico. Terra livre. São Paulo. Ano 19, v. 1, n. 20, jan/jul - 2003.

. BIERAS, A. R. Variabilidade e tendência climática e a produtividade de soja no estado de São Paulo. Rio Claro, 2006, (Tese de Doutorado) - Instituto de Geociências e Ciências Exatas, Universidade Estadual Paulista "Júlio de Mesquita Filho"- UNESP.

.CHRISTOFOLETTI, A. L. H. Estudo sobre a sazonalidade da precipitação na bacia do Piracicaba (SP). (Dissertação de Mestrado) São Paulo: Faculdade de Filosofia, Letras e Ciências Humanas da USP, 1991.

Procedimentos de análise utilizados no estudo da precipitação.

Geociências, São Paulo, v.11, n. 1, 1992

Implicações geográficas relacionadas com as mudanças

climáticas globais. Boletim de Geografia Teórica. Rio Claro, 23(45-45):18-31, 1993. 
.CONTI, J. B. Considerações sobre mudanças climáticas globais e regionais. Boletim de Geografia Teorética. Rio Claro, v. 23, n. 45 - 46, 1993.

.CONTI, J. B. Considerações sobre mudanças climáticas globais. In: SANT 'ANA NETO, J. L. e ZAVATINI, J. A. (org). Variabilidade e mudanças climáticas. Maringá: Eduem, 2000, p. $17-28$.

.DEO at al, On Australian heat waves: Time series analysis of extreme temperature events in Australia, 1950-2005. In MODSIM 2007 International Congress on Modeling and Simulation. Modeling and Simulation Society of Australia and New Zealand, p. 626-635, December (2007).

.FOLHES, M.T.; FISH, G. Caracterização climática e estudo de tendências nas séries temporais de temperatura do ar e precipitação em Taubaté (SP). Revista AmbiÁgua, Taubaté, v.1, n.1, p. 61-7, 2006.

.GALINA, M. H. Mudanças climáticas de curto prazo: Tendências dos regimes térmicos e hídricos e do balanço hídrico nos municípios de Ribeirão Preto, Campinas e Presidente Prudente (SP) no período de 1969-2001. Rio Claro, 2002. Dissertação de Mestrado. Curso de Pós-Graduação em Geografia. Instituto de Geociências e Ciências Exatas. Campus de Rio Claro. Universidade Estadual Paulista.

.GALVANI, E. Sistematização de Dados Quantitativos. In: VENTURINI, L. A. B. (org.) Praticando a geografia: técnicas de campo e laboratório. São Paulo: Oficina de Textos, 2005, p.175-185.

.GERARDI, L. H. de O.; SILVA, B. N. Quantificação em Geografia. São Paulo, SP: Ed. DIFEL, 1981. 163 p.

.GILBERT, R. O. Statistical methods for environmental pollution monitoring. New York: Van Nostrand Reinhold, 320p. (1983).

.GOOSSENS, C; BERGER, A. Annual and seasonal climatic variations over the northern hemisphere and Europe during the last century. Annales Geophysicae, Berlin, v.4, n.B4, p.385-400, (1986).

.HIRSCH, R.M.; SLACK, J. R. A nonparametric trend test for seasonal data with serial dependence. Water Resources Research, v. 20, n.6, p.727 - 732, June (1984).

.KARL, P. D. et al. Indices of climate change for the United States. American Meteorological Society Bulletin, Boston, 1996. Apud, BACK, A. J. Aplicação de análise estatística para identificação de tendências climáticas. Pesquisa Agropecuária Brasileira, v. 36, n. 5, 2001.

.KENDALL, M. G.; Rank correlation methods. London: Charles Griffin, 120p. (1975).

.LOMBARDO, M. A. Mudanças climáticas recentes e ação antrópica. Revista do Departamento de Geografia da USP, São Paulo, v. 8, 1994.

.MANN, H.B. Non-parametric tests against trend. Econometrica, v.13, p.245-259,1945.

.MORETTIN, P. A.; BUSSAB, W. O. Estatística Básica, São Paulo: Editora Atlas, 2004.

.NUNES, L. H. Repercussões globais, regionais e locais do aquecimento global. Terra Livre.

São Paulo, ano 19, v. 1, n. 20 jan/jul - 2003.

Önöz, B; Bayazit, M. C.. The power of statistical teste for trend detection, Turkish J. Eng. Env. Sci., v 27, p.247-251, 2003.

.PACIORNICK, N., MACHADO FILHO, H. Política e Instrumentos Legais e Internacionais da Convenção Quadro das Nações Unidas sobre a Mudança do Clima In: MOREIRA, A. e SCHWARTZMAN, S. (ed.) As Mudanças Climáticas Globais e os Ecossistemas Brasileiros. O Brasil e o Panorama Internacional, Brasília, IPAA, 2000.

.RONCATO, R. A. Variabilidade e tendência climática na região de Campinas (SP) e sua relação com o uso do solo. Rio Claro. 2002. (Tese de Doutorado) - Instituto de Geociências e Ciências Exatas - UNESP.

.SANT'ANNA NETO, J. L, ZAVATTINI, J. A. Variabilidade e mudanças climáticas: implicações ambientais e sócio-econômicas. Maringá: EDUEM, 2000.

.SANT'ANNA NETO, J. L. As chuvas no Estado de São Paulo: contribuição ao estudo da variabilidade climática e tendência da pluviosidade na perspectiva da análise geográfica. São Paulo, 1995, (Tese de Doutorado) - Faculdade de Filosofia, Letras e Ciências Humanas da USP.

.SEN, P. K. Estimates of the regression coefficient based on Kendalls's tau. Journal of the American Statistical Association, v. 63, p. 1379-1389, (1968). 
.SENTELHAS, P. C. et al. Um século de desmatamento: efeitos no Regime Térmico, Pluvial e no Balanço Hídrico em Campinas, S.P., Revista Brasileira de Agrometeorologia, Santa Maria, 1994.

.SNEYERS, R. Sur l'analyse statistique des series dóbservations. Gênevè: Organisation Méteorologique Mondial, 192p. (OMN, Note technique, 143), (1975).

.TAVARES, A. C. Variabilidade e mudanças climáticas. 2001. Tese (Livre-Docência) Instituto de Geociências e Ciências Exatas, Universidade Estadual Paulista "Júlio de Mesquita Filho", UNESP, Rio Claro, 2001.

.VIANELLO, R. L. e ALVES, A. R. Meteorologia básica e aplicações. Viçosa: Imprensa Universitária. 1991.

.YUE, S.; HASHINO, M. Temperature trends in Japan: 1900-1996, Theoretical and Applied Climatology, v. 75, p.15-27, (2003).

.ZAVATTINI, J. A. Variações do ritmo pluvial no oeste de São Paulo e no norte do Paraná: eixo Araçatuba - Presidente Prudente - Londrina. 1983. (Dissertação de Mestrado) - Faculdade de Filosofia, Letras e Ciências Humanas da USP. 